•研究报告・

\title{
《生物多样性公约》中“土著和地方社区”术语在中 国的适用性和评价指标体系
}

李保平 ${ }^{1,2}$, 薛达元 ${ }^{1 *}$

1. 中央民族大学生命与环境科学学院, 北京 $100081 ; 2$. 桂林电子科技大学法学院, 广西桂林 541004

摘要: 《生物多样性公约》第 $8(j)$ 条提出了术语 “土著和地方社区”, 《名古屋议定书》关于遗传资源特别是传统知识获取与惠 益分享的很多重要条款中都涉及该术语。然而, 二者均未对该术语予以定义, 国际社会对该术语的适用范围至今尚未达成一 致，缔约方只能根据公约文本内涵和各国具体国情予以推断和解读。当前的普遍理解包括殖民主义特征的“狭义土著和地方 社区”和仅具有原住民特征的“广义土著和地方社区”两种情况。对于中国而言, “土著和地方社区” 是否与中国少数民族社区概 念上等同或完全不同, 对于全面履行《生物多样性公约》和《名古屋议定书》具有重要意义。本文通过词源分析、定性和定 量化等理论和实证研究，构建了以少数民族具体地方社区为评估单元的“土著和地方社区特征”评价指标体系, 进而对部分少 数民族具体地方社区进行了实际评估。结果表明, 一些至今仍然维持传统生产和生活方式及保留传统文化的少数民族地方社 区具有明显的“土著和地方社区”特征，适用于国际公约的相关规定。这为理解国际上的“土著和地方社区”和中国“少数民族” 提供了思路，为中国履行《生物多样性公约》 《名古屋议定书》中涉及“土著和地方社区”的条款提供了技术支持，也为维护 中国少数民族地方社区在遗传资源及相关传统知识获取与公平惠益分享中的应有权益提供了理论基础。

关键词: 生物多样性公约; 名古屋议定书; 土著和地方社区; 中国少数民族

李保平, 薛达元 (2021) 《生物多样性公约》中 “土著和地方社区”术语在中国的适用性和评价指标体系. 生物多样性, 29, 193-199. doi: $10.17520 /$ biods.2020477.

Li BP, Xue DY (2021) Applicability of term "indigenous and local communities" from the Convention on Biological Diversity in China and the evaluation index system. Biodiversity Science, 29, 193-199. doi: 10.17520/biods.2020477.

\section{Applicability and evaluation index system of the term "indigenous and local communities” of the Convention on Biological Diversity in China}

Baoping $\mathrm{Li}^{1,2}$, Dayuan $\mathrm{Xue}^{\mathrm{i}^{*}}$

1 College of Life and Environmental Sciences, Minzu University of China, Beijing 100081

2 Law School of Guilin University of Electronic Technology, Guilin, Guangxi 541004

\begin{abstract}
Background: The term "indigenous and local communities" is introduced in Article 8(j) of the Convention on Biological Diversity and is used in many important provisions of the Nagoya Protocol on access and benefit sharing of genetic resources, particularly traditional knowledge. However, neither of the two legal instruments has defined the term, and the international community has not reached a consensus on the scope of application of the term. The Parties can only infer and interpret the term according to the connotation of the text of the Convention and the specific national conditions of each country. The current general understanding is that the "narrow sense of indigenous and local communities" with colonial characteristics and the "broad sense of indigenous and local communities" with indigenous characteristics only. For China, it is of great significance to clarify whether "indigenous and local communities" are conceptually equivalent to or different from Chinese ethnic minorities and their communities for the implementation of the Convention on Biological Diversity and the formation of the Nagoya Protocol.
\end{abstract}

收稿日期: 2020-12-24; 接受日期: 2021-02-18

基金项目: 生态环境部生物多样性调查、观测和评估项目

* 通讯作者 Author for correspondence. E-mail: xuedayuan@hotmail.com 
Aims: This article, through the analysis of the origin, the qualitative and quantitative theory and empirical research, selects the important indices for evaluation "indigenous and local communities", and constructs the assessment indicator system of "characteristics of indigenous and local communities" for Chinese ethnic minorities based on the unit evaluation of specific local community. Then, by use of the system, the actual evaluation is made to the local communities of some ethnic minorities in Southwest China.

Results \& Conclusions: The results show that some local ethnic minority communities that still maintain traditional production and life style and retain traditional culture have obvious "indigenous and local community" characteristics, which are applicable to the relevant provisions of international conventions. This article provides the ideas for understanding the international "indigenous and local communities" and domestic "ethnic minorities" in China. Also it provides technical support for China's implementation of the "indigenous and local communities" provisions of the Nagoya Protocol to the Convention on Biological Diversity, and furtherly provides a theoretical basis for safeguarding the rights and interests of local ethnic minority communities in the access to and equitable benefit sharing of genetic resources and related traditional knowledge.

Key words: Convention on Biological Diversity; Nagoya Protocol; indigenous and local community; Chinese ethnic minorities

《生物多样性公约》和《名古屋议定书》中多 个条款涉及“土著和地方社区”, 规定了获取土著和 地方社区的遗传资源及相关传统知识时, 须征得 “土著和地方社区”的“事先知情同意”, 并与当地土 著和地方社区在“共同商定条件”下, 签署体现公平 公正惠益分享的协议。这些规定充分体现了国际社 会对土著和地方社区权益的尊重(薛达元, 2011)。然 而, 由于各国的政治制度和民族自治情况的差异, 对 “土著和地方社区”的理解和定义并不一致, 这对 全面和准确地履行《生物多样性公约》和《名古屋 议定书》形成了阻碍。目前国际上无论是南美洲还 是非洲以及大多数亚洲国家, 都将 “土著和地方社 区” 理解为当地的原住民, 实际上就是广义的“土著 和地方社区”, 与美国、加拿大、澳大利亚、新西兰 存在的殖民化 “狭义土著和地方社区”有一定的差 异。中国不存在殖民化问题, 中国的少数民族社区 是否等同于或近似于广义的“土著和地方社区”? 目 前尚无明确的答案。本文试图通过系统研究“土著 和地方社区”的术语内涵和基本特征，篮选评估“土 著和地方社区” 的指标, 进而构建评价指标体系, 并对中国少数民族社区进行应用验证, 从而分析和 明确中国少数民族社区是否具备国际上 “土著和地 方社区”的基本特征, 为中国全面履行 《生物多样性 公约》和《名古屋议定书》提供技术支持。

\section{“土著和地方社区”的概念}

《生物多样性公约》(以下简称《公约》)第8(j) 条提出: 缔约方应尊重、保存和维持土著和地方社
区体现传统生活方式而与生物多样性的保护和持 久使用相关的知识、创新和做法并促进其广泛应用, 鼓励其公平参与并分享因利用传统知识而获得的 惠益。“土著和地方社区”在《名古屋议定书》(以下 简称《议定书》) 的核心条款中共出现27次，说明“土 著和地方社区”作为遗传资源及相关传统知识的持 有方对实现《公约》公平惠益分享目标的重要性 (SCBD, 2011)。

\section{1 “土著和地方社区”的词源分析}

《公约》中文文本采用“土著和地方社区”对应 “indigenous and local community”。根据中国《辞源》 (1983版)解释, “土著” 原指“世代定居于一地”的群 体, “土著者, 谓有城廓常居, 不随畜牧移徙也”。可 见, “土著”一词在中文中的本意指世代居住于当地 的人, 是相对于“迁徙”而言的一类人群。《牛津高 级词典》(2017版) 和《朗文词典》(2016版) 将 “indigenous”解释为“本土的、当地的”, 描述语言和 文化等特征, 亦无歧视之意。英文中被汉译成“土 著”的词除了“indigenous”还有“aboriginal”、“native” 等。“aboriginal”的英语释义为“相对殖民者而言的 “先住人”, 一般特指印第安人、大洋洲毛利人、澳 洲土著等。“native”在英语中被释义为“先于白种人 来到一个国家的人”, 一般指美洲土著, 有殖民含 义。此外, “tribal” 也有部落、土著之意, 多用来描述 非洲土著部落。公约文本采用“indigenous people” 不包含政治歧视色彩, 表现出国际公约的严谨性。

“local community”被译为“地方社区”, 是指社 会群体聚集在某一地理领域形成的有生活关联的 
集体。根据国际法惯例, “社区”不能作为法律主体行 使相应的权利, 只有 “土著人民”才能作为法律主体 享有相应权利。“地方社区” 是否享有某些优先权, 取决于国家立法。

\section{2 《公约》对“土著和地方社区”术语的讨论}

《公约》第8(j) 条和相关条款问题不限成员名 额特设工作组对术语“土著和地方社区”进行了多次 讨论, 形成了一些阶段性结论, 主要包括: 第8条(j) 款有关“土著和地方社区”范畴的专家组报告和《生 物多样性公约》第十二次缔约方大会关于使用“土 著人民和地方社区”术语对 《生物多样性公约》及 《名古屋议定书》的影响分析报告(SCBD, 2017a)。 这些报告初步达成了部分共识: 土著人民是处于多 元文化和政治状态下, 以口头传统和代际传播传统 知识、信仰和习俗, 对自然具有依赖性, 对于生物 资源管理和生物多样性保护起关键作用的群体; “地方社区” 是与 “土著人民”的生存有密切关系, 能 体现其特殊的政治、经济、文化等多因素的小地域 范围。关于术语 “土著和地方社区”适用范围的有关 讨论仍在继续。缔约方大会同时呼吁国际劳工组 织、世界知识产权组织等其他国际组织推动对“土 著和地方社区” 相关问题的研究和讨论 (SCBD, 2017b)。

因此, 根据《生物多样性公约》和《名古屋议 定书》, “土著和地方社区” 是一个复合概念的法律术 语, 可以理解为生活在特定地理区域范围内可通过 技术指标加以识别的特殊人群的集合。

\section{3 其他国际组织对“土著和地方社区”的理解}

世界自然保护联盟将 “社区”定义为“聚居在某 地域范围内的成员组成的社会生活共同体, 社区成 员共享该地理区域内的自然资源、生产知识及技术 实践等生计要素。社区中成员一般具有固定的人口 数量、社会组织类型和文化特征(包括语言、行为规 范、价值观等), 社区往往作为一个有特定能力的小 型政治体进行运作” (薛达元等, 2012)。

国际劳工组织大会通过的《土著和部落人民公 约》(简称《169号公约》)采用了广义的理解方式, 将 土著分为两种情况: (1)在其所属国家或该国某一地 区被征服或被殖民化时存在的人口; (2)在其目前的 国界被确定时, 即已居住在那里的人口后裔, 他们 部分或全部保留本民族的社会、经济、文化等特征 (ILO, 1989)。
《世界银行 OP 4.10 》规定了“indigenous peoples” 是指在社会和文化特征上有别于主流社会, 处于不利境地的弱势社会群体。同时给出识别土著 群体较为详细的标准: (1)日常生活紧密依附其固有 生存土地(territory)和土地上的自然资源; (2)具有自 我认同或者被主流群体认为具有某种独特文化的 群体; (3)具有自己的本土语言(local language); (4)保 持各自的生产、生活方式。世界银行对“土著人民” 的理解更多是对某个特殊群体特征的描述和识别 (金慧华, 2009)。

\section{4 中国对“土著”和“少数民族”的一般理解}

中国是统一的多民族国家, 不存在殖民意义的 狭义“土著”和土著问题。因语言翻译技术等原因, 中国政府和学者对“土著”一词比较敏感, 一般认为 中国不存在像美洲和澳洲等地区的殖民意义的土 著人和历史遗留问题。国内学者多从人类学、民族 学的视角对 “土著”和“少数民族”进行了相关研究。 他们普遍认为中国少数民族至今仍保留着与生存 环境有紧密联系的较为原始和传统的生产和生活 方式, 这些特征与国际社会的土著民族有很多相似 性, 在权利保护方面应相互借鉴。在中国公开出版 和发行的刊物中, 经常看到“少数民族”与“土著”之 间的语境互换。例如, 学者陈廷亮等在其论著中将 湘西土家族苗族等少数民族称为“土著民族”, 将其 民族文化称之为“土著文化” (陈廷亮和王庆, 2012)。

\section{2}

\section{“土著和地方社区”的关键指标}

本研究认为, 中国许多少数民族社区至今仍然 保存着与国际公约中“土著和地方社区”相似的特征, 可依据国际社会对“土著”和“地方社区”的界定标准, 梳理出“土著和地方社区”的关键指标。通过实证比 较研究, 分析“少数民族社区”与“土著和地方社区” 特征异同。

\section{1 体现“土著和地方社区” 内在基本特征的指标}

内在特征是指“土著和地方社区”本身所拥有的 权利、政治制度与知识特征, 以及体现其传统生产 和生活的特征。根据国际公约和不同国际组织对 “土著人民”、“社区”以及“土著和地方社区”的释义, 本研究首先系统梳理出 “土著和地方社区”的基本特 征, 指标因子包括自我认同、世居性、拥有与生物 多样性相关的传统知识等16项, 这些指标因子能较 全面地反映出“土著和地方社区”的政治、经济和文 
化等状况。然后应用德尔菲法对民族学、法学、民 族生态学等领域的30位专家进行咨询, 对16项关键 指标进行篮选，最终确定了(a)自我认同、(b)世居 性、(c)自决权或自治权、(d)资源与环境权、(e)传统 文化权和(f)保留传统的生产生活方式等6个核心评 价指标，进而对各指标进行权重分析。步骤如下: (1) 设计有关“土著和地方社区”特征指标的意见征询表; (2)选择了民族宗教事务管理局、农业农村局、林业 与草原局、高等院校科研机构等涉及民族学、生态 学、法学等学科领域专家 30 人，向其提供有关背景 资料后，通过问卷和半结构式访谈等咨询意见; (3) 征询不同专家意见后, 进行数理统计, 结果见表1; (4)根据专家反馈的结果进行相关指标的修正; (5)经 过多轮专家意见征询, 形成结论。其中: (1) X1-Xn 为样本数量, 表示有 $\mathrm{n}$ 个专家参与问卷打分; (2) Xna-Xnf表示第 $\mathrm{n}$ 个专家对第 $\mathrm{a}$ 个指标到第 $\mathrm{f}$ 个指标 的打分值; (3) $\sum 6 \mathrm{i}$ 表示所有指标的分数之和 $(\mathrm{i}=1$, $2, \ldots 6)$; (4)权重值 $r=u i / \sum 6 i u i$, 其中ui表示第 $\mathrm{i}$ 个指标 的平均得分; 指标权重计算结果见图1。权重大小排
列依次为: 保留传统生产生活方式 $\rightarrow$ 自我认同 $\rightarrow$ 自 决权或自治权 $\rightarrow$ 拥有传统文化权 $\rightarrow$ 世居性 $\rightarrow$ 资源 环境权。评价指标权重值越大表示该指标在评价体 系中越重要, 可作为评价标准中的重要参考; 权重 值低的在现实评价中可予以忽略，这为后期的实证 研究提供了理论基础。

\section{2 体现“土著和地方社区”外部特征的指标}

外部特征主要指“土著和地方社区”与所在地区 社会、经济、文化和资源利用相关的特征。本研究

表1 “土著和地方社区”各项指标的专家打分值及权重计算 Table 1 The experts scoring value and weight calculation of "indigenous and local communities"

\begin{tabular}{lllllll}
\hline $\begin{array}{l}\text { 样本数量 } \\
\text { Sample size }\end{array}$ & \multicolumn{7}{l}{ 指标排序 } \\
\hline $\mathrm{X}$ & $\mathrm{a}$ & $\mathrm{b}$ & $\mathrm{c}$ & $\mathrm{d}$ & $\mathrm{e}$ & $\mathrm{f}$ \\
$\mathrm{X} 1$ & $\mathrm{X} 1 \mathrm{a}$ & $\mathrm{X} 1 \mathrm{~b}$ & $\mathrm{X} 1 \mathrm{c}$ & $\mathrm{X} 1 \mathrm{~d}$ & $\mathrm{X} 1 \mathrm{e}$ & $\mathrm{X} 1 \mathrm{f}$ \\
$\mathrm{X} 2$ & $\ldots$ & & & & & $\ldots$ \\
$\ldots$. & $\ldots$ & & & & & $\ldots$ \\
$\mathrm{Xn}$ & $\mathrm{Xna}$ & $\mathrm{Xnb}$ & $\mathrm{Xnc}$ & $\mathrm{Xnd}$ & $\mathrm{Xne}$ & $\mathrm{Xnf}$ \\
权重值 Weight & $\overline{\mathrm{a}} / \sum 6 \mathrm{ia}$ & $\ldots$ & & & $\ldots$ & $\overline{\mathrm{f}} / \Sigma 6 \mathrm{i} \overline{\mathrm{f}}$ \\
\hline
\end{tabular}

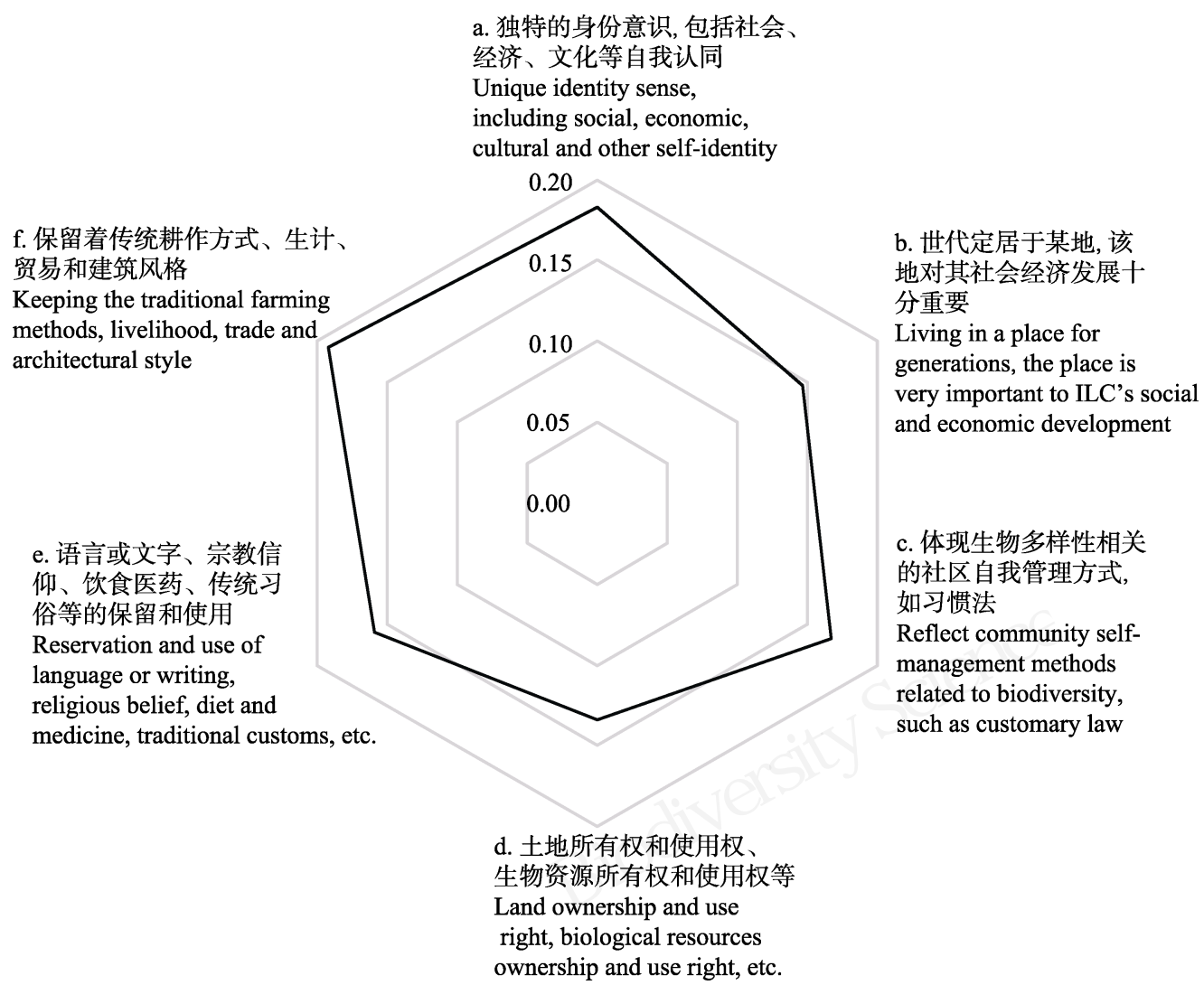

图1 “土著和地方社区”关键指标節选中各指标因子权重排序

Fig. 1 The "indigenous and local community” index factor weight 
将 “土著和地方社区评价指标体系” 作为目标层, 进 一步分为 4 个一级指标: 社会、经济、文化和资源环 境, 每个一级指标均能较为全面地反映出土著和地 方社区的整体特征，根据其特征类型再细分为 $3-4$ 个二级指标; 二级指标可直接通过观测获取数据和 信息, 部分二级指标需通过辅助指标进一步量化或 细化。

\subsection{1 社会层面指标}

社会层面的指标可表征“土著和地方社区”的社 会发展现状, 包括社会组织、政治制度和受教育程 度等社会活动要素。政治制度包括社会内部治理、 道德规范、社区规约、风俗习惯等因素。辅助量化 指标的选择及相关说明: (1)世居人口数量和结构的 稳定性是国际认定土著和地方社区最基本的指标。 (2)文化认同、政治认同和民族认同能较好反映出土 著和地方社区的自我认同。(3)族长、寨老制等社会 组织及社区习惯法反映出土著和地方社区内部的 社会制度。

\subsection{2 经济层面指标}

“土著和地方社区”的经济发展方式不同于主流 社会, 经济层面指标主要体现在其传统生计、传统 生产方式、产业组成结构、传统贸易等方面。辅助 或量化指标的选择及相关说明: (1)传统生计指标包 括当地社区依靠传统农作物、畜禽的种养殖和传统 贸易为生等情况, 可通过调查其传统生计的种类和 数量反映当地社区的经济发展状况。(2)土地和资源 的优先开发利用指标反映该民族社区对土地利用 和自然资源的开发利用是否享有优先开发权、使用 权和收益权。(3)传统生产方式指从事传统农耕、狩 猎、捕鱼以及各种手工艺等的种类和数量, 该指标 能反映出地方社区对固有土地和自然资源的依附 性情况。

\subsection{3 文化层面指标}

文化特征最能反映出土著和地方社区的持久 性和稳定性, 文化因素也是土著和地方社区生存与 发展的标志和载体, 关乎该族群的未来走向。本研 究根据国际“土著和地方社区”的文化特征, 将以下 指标作为文化层面的指标元素: (1)语言或文字及使 用情况; (2)传统生产、生活方式; (3)传统文化习俗、 习惯; (4)独特的精神信仰、文化价值观等。辅助或 量化指标的选择及相关说明: (1)语言、文字的使用 人数和比例反映出该族群对语言、文字的认同; (2)
传统生产生活方式反映出该族群是否具有信守和 传承本民族文化的意愿。

\subsection{4 资源和环境层面指标}

本研究中的资源主要指生物遗传资源及相关 传统知识, 具体包括生物遗传资源的种类和数量, 可利用生物多样性指数的计算方法进行评价。文化 资源主要指在长期开发利用生物遗传资源过程中 积累的传统知识, 包括传统利用农业遗传资源和医 药资源的知识、传统生产生活方式及技术创新、保 护生物多样性的传统文化习俗, 以及开发利用传统 地理标志产品等方面的知识(薛达元, 2019)。量化指 标的选择及相关说明: (1)地方农作物和畜禽种类和 数量指标反映出传统生物遗传资源的留存和利用 情况。(2)传统食品的种类和数量反映出传统利用生 物的工艺应用和保留情况。(3)传统医药的种类和数 量反映出当地传统医药知识传承情况。(4)民族医生 的数量反映出该民族对传统医药的保留态度情况。 (5)传统文化习俗的种类和数量指标反映出与生物 多样性相关特有文化的丰富度。(6)传统地理标志产 品数量指反映当地特色生物资源和传统知识的开 发利用状况。

\section{3}

\section{“土著和地方社区”评价指标体系的构延}

基于上述评价指标的篮选和确定, 进一步研究 并构建评估 “土著和地方社区” 的指标体系, 然后通 过实证应用, 分析“土著和地方社区”评价体系对中 国少数民族社区的应用, 进而得出中国少数民族社 区是否具有 “土著和地方社区”的特征。

\section{1 评价指标体系的设计原则}

(1)科学性原则。科学性原则旨在采用科学方法 对各要素进行分类评价, 根据不同的指标因素对 “土著和地方社区”的客观识别做出科学判断。本研 究构建的 “土著和地方社区” 指标体系在现有科学理 论的原则下, 能尽可能客观全面地反映出国际社会 对土著和地方社区的本质描述, 以及土著和地方社 区的社会结构、经济发展和文化属性等方面的内在 特点。

(2)系统性原则。“土著和地方社区” 是经过国际 社会反复讨论, 综合其社会结构、经济、文化发展 以及资源环境等多种因素而确认的重要法律用语, 作为一个复合概念的法律术语, 其特征要素之间相 互影响、相互制约。系统性原则综合考虑评价体系 
的完整性和代表性，可系统反映出土著和地方社区 的特征。

(3)定性和定量相结合原则。为了科学构建“土 著和地方社区”的评价指标体系, 指标因素的选择 除了考虑当前获取数据信息的可描述性，还尽可能 将部分指标量化处理，做到定性指标可赋值。

(4)可操作性原则。“土著和地方社区”评价指标 体系应具有实践指导性，便于政府管理和科研人员 根据需要对其他时空范围的原住民群体进行比较、 评估和验证, 具备可观察和测量性, 能针对性地解 决土著和地方社区的识别和适用范围的确定。

\section{2 “土著和地方社区”评价指标体系的构建}

将实证研究获取的第一手数据进行定性和定 量化处理，各指标因子尽可能反映出评价系统的多 指标和多层次性。通过明确研究目标和研究对象, 进一步修正初设体系中的各项指标值，对上述不同 层级因子进行专家打分法确认权重, 得出“土著和
地方社区”的评价指标体系(表2)。该评价指标体系 共计 4 个一级指标、 11 个二级指标和 15 个辅助指标。

\section{4 “土著和地方社区”指标体系的应用验访}

根据上述“土著和地方社区”评价指标体系，通 过咨询专家意见，在中国广西选取了具有典型性和 代表性的少数民族社区进行有效性验证。具体选择 了广西马山壮寨、那坡黑衣壮寨; 环江毛南族上南 乡、中南乡、下南乡和金秀瑶族六段屯等进行应用 验证。研究采用调查问卷、座谈会、半结构式访谈, 运用定性与定量相结合等民族生态学田野调查方 法，对照生态环境部(原环境保护部)2014年公布的 《生物多样性相关传统知识分类、调查与编目技术 规定(试行)》和“土著和地方社区”评价指标体系的 定性和辅助量化指标因子，研究这些少数民族社区 的社会、经济、文化以及环境资源等特征，分析比 较这些中国的少数民族社区与“土著和地方社区”特

表2 “土著和地方社区”评价指标体系

Table 2 The evaluation index system of "indigenous and local communities"

\begin{tabular}{|c|c|c|c|}
\hline $\begin{array}{l}\text { 一级指标 } \\
\text { First indicators }\end{array}$ & $\begin{array}{l}\text { 一级指标权重 } \\
\text { First indicator weight }\end{array}$ & $\begin{array}{l}\text { 二级指标 } \\
\text { Secondary indicators }\end{array}$ & $\begin{array}{l}\text { 二级指标权重 } \\
\text { Secondary indicator weight }\end{array}$ \\
\hline \multirow[t]{3}{*}{ 社会 Society } & \multirow[t]{3}{*}{0.2635} & 世居性 Habitability & 0.0852 \\
\hline & & 自我认同和身份意识 Self identity and consciousness & 0.0910 \\
\hline & & $\begin{array}{l}\text { 社会组织制度和习惯法 } \\
\text { Social organization system and customary law }\end{array}$ & 0.0763 \\
\hline \multirow[t]{3}{*}{ 经济 Economy } & \multirow[t]{3}{*}{0.1761} & 传统生计 Traditional livelihood & 0.0535 \\
\hline & & 经济自主权 Economic autonomy & 0.0429 \\
\hline & & 传统生产方式 Traditional mode of production & 0.0596 \\
\hline \multirow[t]{3}{*}{ 文化 Culture } & \multirow[t]{3}{*}{0.2873} & $\begin{array}{l}\text { 语言或文字的保留与传承 } \\
\text { Preservation and inheritance of language or writing }\end{array}$ & 0.0897 \\
\hline & & $\begin{array}{l}\text { 生活习俗、节日等民族文化 } \\
\text { Life customs, festivals and other national cultures }\end{array}$ & 0.0920 \\
\hline & & $\begin{array}{l}\text { 宗教信仰等精神价值体系 } \\
\text { Religious belief and other spiritual value system }\end{array}$ & 0.0767 \\
\hline \multirow[t]{2}{*}{$\begin{array}{l}\text { 资源环境 } \\
\text { Resources and environment }\end{array}$} & \multirow[t]{2}{*}{0.3015} & $\begin{array}{l}\text { 独特的生物资源, 生物多样性丰富 } \\
\text { Unique biological resources, rich biodiversity }\end{array}$ & 0.0851 \\
\hline & & $\begin{array}{l}\text { 生物多样性相关传统知识丰富 } \\
\text { Rich traditional knowledge related to biodiversity }\end{array}$ & 0.0952 \\
\hline
\end{tabular}

\section{Box 1 15个辅助指标及量化}

(1)世居人口的数量和结构以及分布范围的稳定性; (2)文化认同、政治认同和民族认同的人数及比例; (3) “寨老制”等 社会制度和族群内部规则，如“隆款”、“榔规”等习惯法; (4)土地使用和资源优先开发权和收益权; (5)传统农耕、狩猎、 捕鱼等经济生产方式的种类和数量; (6)从事传统生计的人数和比例; (7)本民族语言文字的使用人数和比例; (8)民族宗教信仰 的人数和比例; (9)传统居住风格、传统生活习俗等民族文化的丰富度; (10)传统农作物、畜禽品种的种类和数量; (11)传统食品 的种类和数量; (12)传统医药(药材、诊疗技术、方剂等)的种类和数量; (13)民族医生的数量及比例; (14)生物多样性保护相关 传统文化习俗的种类和数量; (15)传统地理生物标志产品的种类和数量。 
征的异同。

结果表明, 并非所有的少数民族社区都符合 “土著和地方社区”的特征标准。调研中发现, 只有 广西那坡黑衣壮寨、金秀六段屯瑶寨和环江县毛南 族下南乡符合“土著和地方社区”评价体系的关键指 标。由于中国少数民族分布区域广衰, 加之长期地 理隔离等原因，各民族间形成显著的特征差异。即 使是同一少数民族, 不同支系或不同地域其社会经 济发展状况不平衡，民族文化包括语言文字的使 用、民俗习惯、宗教信仰等方面也表现出很大差异 性。对于那些地理位置优越、交通便捷的少数民族 社区, 其经济发展水平相对较高, 生活方式、思想 观念、民族文化等因素也在渐渐脱离传统。对照构 建的评价指标体系, 这些少数民族社区已经不符合 “土著和地方社区”的标准。对于保留了“土著和地方 社区”核心特征的少数民族支系或社区，可视其为 土著和地方社区。

\section{5 结论}

《公约》中重要术语“土著和地方社区”的明晰 对于缔约方实施获取与惠益分享制度至关重要。本 研究构建的“土著和地方社区”评价指标体系可为国 家在履行涉及 “土著和地方社区”国际公约时提供技 术支持。鉴于中国各少数民族在地理分布、族群结 构、经济发展水平、受外来文化影响的复杂性和差 异性, 不能笼统地将其完全等同于或不同于国际上 的“土著和地方社区”, 而需要根据少数民族各个支 系和不同地方社区的具体特征进行定量化评估，即： 以民族支系或者具体地方社区作为评估单元，应用 构建的“土著和地方社区”评价指标体系进行逐案评 估，从而在民族支系和具体地方社区的层次上明确 是否具有 “土著和地方社区”特征。由此可见, 那些 至今仍然保留着传统生产和生活方式的民族社区, 大多都具有 “土著和地方社区”的特征。而那些受外 来文化影响，逐渐丧失传统生产生活方式的民族社 区，已经不具有 “土著和地方社区”的特征。对于具 有 “土著和地方社区”特征的民族社区，可以适用 《生物多样性公约》和《名古屋议定书》的规定, 以 国家和地方立法方式, 确保他们对其遗传资源及相 关传统知识的持有者权益, 通过实施“事先知情同 意”和“共同商定条件”等原则, 公平公正地获得因 利用其遗传资源及相关传统知识所产生的惠益。

\section{参考文献}

Chen TL, Wang Q, Chen AL, Tang T, Zhou R (2012) Discussion on countermeasures for the protection and inheritance of intangible cultural heritage of Xiangxi's minorities. Minzu Tribune, (6), 89-95. (in Chinese with English abstract) [陈廷亮，王庆，陈奥琳，唐婷，周荣 (2012) 湘西少数民族非物质文化遗产保护与传承对策探 讨. 民族论坛, (6), 89-95.]

ILO (International Labor Organization) (1989) Indigenous and Tribal Peoples Convention. https://www.un.org/ruleoflaw/file s/wcms_100897.pdf. (accessed on 2020-12-10)

Jin HH (2009) The impact of development projects on the environmental rights of indigenous people: Focusing on the indigenous policies of the World Bank. Political Science and Law, (7), 137-142. (in Chinese) [金慧华 (2009) 论发展项 目对土著居民环境权的影响：以世界银行土著民政策为 中心. 政治与法律, (7), 137-142.]

SCBD (Secretariat of the Convention on Biological Diversity) (2011) Nagoya Protocol on access to genetic resources and the fair and equitable sharing of benefits arising from their utilization to the Convention on Biological Diversity. https://www.cbd.int/abs/doc/protocol/nagoya-protocol-en.pdf. (accessed on 2020-12-16)

SCBD (Secretariat of the Convention on Biological Diversity) (2017a) Glossary of relevant key terms and concepts within the context of article $8(\mathrm{j})$ and related provisions. https://www.cbd.int/doc/c/1d3f/4110/c922549b825d2fd4e58 9cf79/wg8j-10-03-en.pdf. (accessed on 2020-12-16)

SCBD (Secretariat of the Convention on Biological Diversity) (2017b) Compilation of views on the integration of article 8(j) and provisions related to indigenous peoples and local communities in the work of the convention and its protocols. https://www.cbd.int/doc/meetings/tk/wg8j-10/information/wg 8j-10-inf-04-en.pdf. (accessed on 2020-12-16)

Xue DY (2011) Analysis for the main elements and potential impacts of Nagoya Protocol. Biodiversity Science, 19, 113-119. (in Chinese with English abstract) [薛达元 (2011) 《名古屋议定书》的主要内容及其潜在影响. 生物多样 性, 19, 113-119.]

Xue DY, Qin TB, Cai L (2012) The Regime of Access and Benefit Sharing for Traditional Knowledge Associated with Genetic Resources. China Environmental Science Press, Beijing. (in Chinese) [薛达元, 秦天宝, 蔡蕾 (2012) 遗传 资源相关传统知识获取与惠益分享制度研究. 中国环境 科学出版社, 北京.]

Xue DY (2019) Conservation and outlook of traditional knowledge associated with biodiversity. Biodiversity Science, 27, 705-707. (in Chinese) [薛达元 (2019) 生物多 样性相关传统知识的保护与展望. 生物多样性, 27 , 705-707.]

(责任编委: 杨庆文 责任编辑: 周玉荣) 